\title{
PRECIPITAÇÃO INCIDENTE E FLUXO DE ATRAVESSAMENTO DAS CHUVAS EM TRÊS ESTÁGIOS SUCESSIONAIS DE FLORESTA ATLÂNTICA NO MACIÇO DA PEDRA BRANCA, RIO DE JANEIRO ${ }^{1}$
}

\begin{abstract}
Henrique Fürstenau Togashi ${ }^{2}$, Rita de Cássia Martins Montezuma ${ }^{3}$ e Adriana Filgueira Leite ${ }^{4}$
RESUMO - São apresentados os resultados de fracionamento da precipitação de chuva em três tipologias vegetais através dos fluxos de atravessamento e precipitação incidente em estudo realizado na sub-bacia do Caçambe, maciço da Pedra Branca, Rio de Janeiro. No período de 04/11/09 a 04/11/10, foram realizadas 27 coletas após os eventos de chuva. Utilizaram-se 12 pluviômetros em uma área de floresta secundária avançada, seis em uma capoeira e seis na borda entre as tipologias. Os resultados de fluxo de atravessamento, $89 \%$ na borda, $94 \%$ em mata secundária inicial e $75 \%$ em floresta secundária avançada, estão de acordo com valores médios da Floresta Atlântica. Houve aumento de interceptação com o avanço do estágio sucessional, o que sugere a importância da preservação florestal para garantir interceptação mais eficiente da água da chuva, em especial em uma cidade sujeita a alagamentos, como o Rio de Janeiro.
\end{abstract}

Palavras-chave: Fluxo de atravessamento, Precipitação incidente e Floresta Atlântica.

\section{GROSS RAINFALL AND THROUGHFALL IN THREE SECONDARY SUCCESSION GRADIENTS OF ATLANTIC RAIN FOREST ON PEDRA BRANCA MASSIF, RIO DE JANEIRO}

\begin{abstract}
This paper presents results for gross rainfall and throughfall regimes found in three successional phases in a stand located at Caçambe sub-basin, Pedra Branca massif, Rio de Janeiro. It was carried out 27 samplings after rain events from 04/11/09 to 04/11/10. Gross rainfall and throughfall were measured with 12 rain gauges in an area of advanced secondary forest, 6 in an early secondary succession and 6 in the edge. Average throughfall was $89 \%$ in the edge, $94 \%$ in initial secondary succession and $75 \%$ in advanced secondary forest. Those values are in agreement with the values found in the literature for the Atlantic Rain Forest. Throughfall decreased simultaneously to the advance of the secondary succession. Interception results imply the importance of forest conservation in cities vulnerable to flooding such as Rio de Janeiro.
\end{abstract}

Keywords: Throughfall, Gross rainfall and Atlantic rain forest.

\section{INTRODUÇÃO}

Os ecossistemas florestais são reconhecidos como fornecedores de recursos e prestadores de serviços ambientais. Quando preservados, desempenham papel no controle erosivo, na amenização da temperatura, na filtragem da poluição, na regulação de elementos climáticos locais como umidade e chuvas, além de influenciarem no abastecimento de reservatórios como lagos, aquíferos e represas. A ação humana em diferentes magnitudes, como a retirada de madeira para corte, caça, queimadas, pastos, diferentes cultivos agrícolas,

\footnotetext{
${ }^{1}$ Recebido em 25.03.2011 aceito para publicação em 04.06.2012..

2 Fundação Oswaldo Cruz, FIOCRUZ, Pontifícia Universidade Católica do Rio de Janeiro. E-mail: $<$ furstenautogashi.henrique@mq.edu.au>.

${ }^{3}$ Pontifícia Universidade Católica do Rio de Janeiro, Departamento de Geografia. E-mail: < montezum@puc-rio.br>.

${ }^{4}$ Universidade Federal Fluminense, Instituto de Ciências da Sociedade e Desenvolvimento Regional, Departamento de Geografia. E-mail:<adrianafilgueiraleite@id.uff.br>.
} 
ocupação rural, ocupação urbana efetiva ou próxima, emissão de poluentes das mais diversas naturezas, provocam efeitos dificilmente previsíveis.

Os estudos em interceptação da chuva pela cobertura vegetal são críticos para o gerenciamento de áreas sujeitas a alagamentos, bem como para prevenção de potenciais problemas causados por mudanças climáticas, como alteração do comportamento das chuvas diárias (WALLACE; MCJANNET, 2008). Os monitoramentos na dinâmica de chuvas e interceptação vegetal buscam o entendimento de processos da ação da água na floresta sob a forma de precipitação, regulação, alterações, armazenamento e análise da ciclagem de nutrientes e poluentes nesse sistema.

O dossel vegetal é responsável pelo primeiro fracionamento da água da chuva. Interceptação da precipitação é o processo em que a chuva atinge as superfícies vegetais, sendo subsequentemente redistribuída. A cobertura vegetal atua interceptando e armazenando parte da precipitação em folhas, troncos e galhos. Uma fração da chuva capturada é devolvida à atmosfera através da evapotranspiração durante e após o evento. Quando a capacidade de retenção de água por parte da vegetação atinge a saturação no dossel, ocorrem o fluxo de atravessamento (At) e o fluxo de tronco $(\mathrm{Ft})$. O nome precipitação interna $(\mathrm{Pi})$ se dá à soma de At + Ft. Esses dois processos são a forma como a chuva se move na vegetação em direção ao solo. No fluxo de atravessamento, a água da chuva penetra o dossel entre os espaços das folhas e o gotejamento delas. O fluxo de tronco guia a água por galhos, convergindo no tronco. A chuva atinge, então, a serapilheira que também intercepta parte dessa água, armazenando-a (DUNNE; LEOPOLD, 1978; COELHO NETTO, 2005).

O total de interceptação depende da natureza da cobertura vegetal e das características da precipitação, como intensidade, duração, frequência e evaporação. Em áreas vegetadas, os maiores fatores-controle da interceptação são tipo, densidade, forma e idade das folhas. Regra geral, quanto mais densa a folhagem, maior o armazenamento da interceptação. A idade e o manejo humano afetam diretamente a densidade da cobertura. Os resultados médios de interceptação para Mata Atlântica variam de $6 \%$ a $68 \%$ da precipitação total, sendo os valores entre $10 \%$ e $20 \%$ os mais registrados (Tabela 1 ).

Revista Árvore, Viçosa-MG, v.36, n.5, p.907-917, 2012
Apesar de extensa literatura internacional no tema, estudos representativos da interceptação na Floresta Atlântica, com continuidade, ainda são restritos a dois núcleos no Brasil: Cunha em São Paulo e Paranaguá no Paraná (BERTÉ et al., 2003; CICCO et al., 2007). Torna-se evidente a necessidade de desenvolver esses estudos, contemplando outros polos. O conhecimento atual no Brasil ainda requer investigações básicas no tema, como o interesse pelo fracionamento físico da precipitação em fluxo de atravessamento, fluxo de tronco, interceptação e quantificação de nutrientes influenciada por fatores como sazonalidade e diferentes coberturas vegetais.

O objetivo deste trabalho foi estudar o fracionamento da precipitação de chuva em três tipologias vegetais, através dos fluxos de atravessamento e precipitação incidente. A parcela é constituída por Floresta Atlântica, situada no maciço da Pedra Branca, Rio de Janeiro, e inserida em um contexto de pressão urbana crescente. A ocupação urbana no sul do maciço da Pedra Branca, além de consolidada, experimenta grande e contínuo crescimento. O aumento da exploração dos recursos florestais e do fluxo de poluentes pode provocar redução na capacidade de interceptação da chuva pela retirada da cobertura vegetal e, mesmo, pela fragilização dos processos ecológicos.

\section{MATERIAL E MÉTODOS}

\section{1. Área de estudo}

O estudo foi conduzido na sub-bacia do Caçambe, maciço da Pedra Branca, Rio de Janeiro. Aárea amostral encontra-se à meia encosta barlavento, em altitude de $180 \mathrm{~m}$. O maciço situa-se entre as coordenadas 22Ú53' e 23Ú00 sul e 43Ú23' e 43Ú32' oeste. Aárea é caracterizada pelo IBGE (1992) como uma Floresta Ombrófila Densa Submontana, de tipologia climática subúmida, com pouco ou nenhum déficit hídrico. O clima da região, segundo Köppen, é caracterizado como Af - clima tropical quente e úmido. A temperatura média anual é superior a 22 ÚC, variando no verão entre 30 ÚC e 32 ÚC e apresentandose ameno no inverno, com temperaturas acima de 18ÚC (OLIVEIRA, 2005). Oliveira (2005) e Oliveira e PennaFirme (2005) registraram precipitação anual média de $1.187 \mathrm{~mm}$, compatível com a média da cidade do Rio de Janeiro. Há pequena deficiência hídrica entre os meses de julho e outubro. 


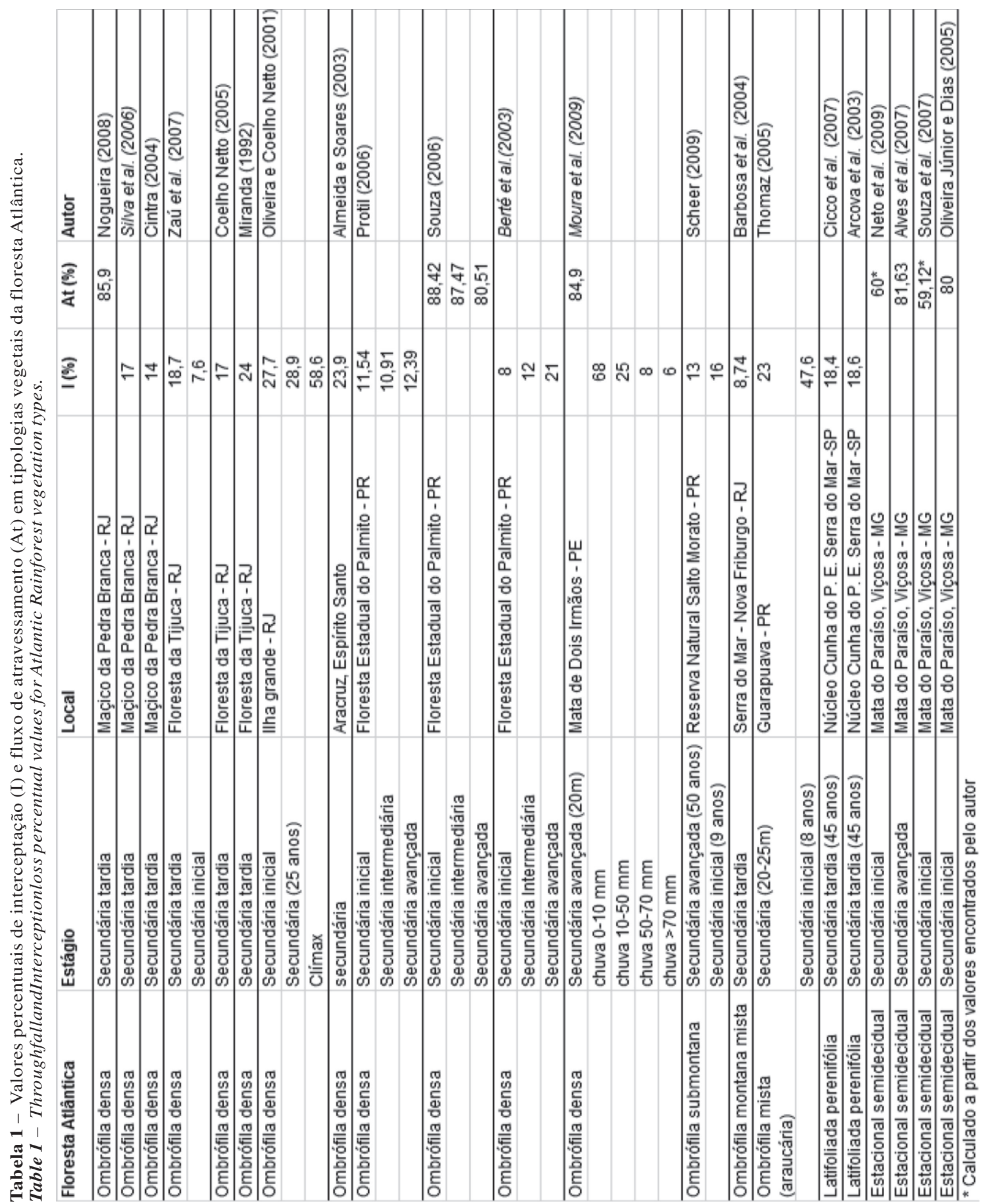


Os solos, devido à declividade acentuada, são bastante rasos, variando de 40 a $60 \mathrm{~cm}$ de profundidade nas encostas. A geologia do local se destaca por apresentar rochas ígneas, o batólito da Pedra Branca, de composição granodiorídica/tonalítica a tipos ácidos de composição granítica, com marcante estrutura fluidal proporcionada pelos cristais de feldspato. A maior parte do solo é derivada de gnaisses e granitos com alta concentração de caulinita, o que os torna nutricionalmente pobres. Especificamente no Caçambe, os latossolos ocupam as encostas mais elevadas, que são solos rasos e associam-se com cambissolos, solos litólicos e podzólicos, estes últimos recobrindo, principalmente, as vertentes mais suaves de menor altitude (PENHA, 1984; OLIVEIRA, 2005; OLIVEIRA; PENNA-FIRME, 2005).

Adjacente a esse domínio de encosta, encontra-se a baixada (planície) de Jacarepaguá, uma área com ocupação urbana em acentuado crescimento e sujeita a frequentes alagamentos. Segundo Montezuma e Oliveira (2010), a ocupação da planície de Jacarepaguá ocorreu em áreas já anteriormente sujeitas a alagamentos. O caráter de impermeabilização do solo na ocupação antrópica em uma área vulnerável a alagamentos os potencializou.

A dinâmica pluviométrica na sub-bacia do Caçambe e no maciço da Pedra Branca é controlada, principalmente, pelas massas de ar. No Sudeste brasileiro, as massas que podem influenciar no clima, em magnitudes diferenciadas, são a massa equatorial continental (MEC), massa tropical atlântica (MTA) e a massa polar atlântica (MPA). As massas equatoriais do Atlântico (MEA) Norte e Sul, massa tropical continental (MTC) e massa tropical pacífica (MTP) têm pouca ou nenhuma influência direta sobre o Rio de Janeiro (MENDONÇA; DANNIOLIVEIRA, 2007). O efeito orográfico é outro decisivo fator no controle da precipitação local. Dereczynski et al. (2009) e Coelho Netto (2007) observaram que o domínio montanhoso é mais chuvoso em comparação com as planícies em diversos pontos da cidade do Rio de Janeiro. Os maciços da Pedra Branca, da Tijuca e do Gericinó-Mendanha recebem os máximos pluviométricos de toda a cidade. Oliveira e Hack (2004) verificaram que em uma Floresta Atlântica na Ilha Grande a chuva em altitude $(300 \mathrm{~m})$ foi cerca do dobro em relação à no nível do mar $(20 \mathrm{~m})$.

\subsection{Procedimentos metodológicos}

No dia 4 de novembro de 2009, foram instalados 24 pluviômetros em um transecto com gradiente de três estágios sucessionais distintos. Na floresta secundária avançada (SA), reutilizou-se o posicionamento de trabalho anterior realizado na área por Nogueira (2008), com 12 pluviômetros novos. Na tipologia borda (BD) e na tipologia secundária inicial (SI), utilizaram-se seis pluviômetros em cada. A distância entre os pluviômetros foi de 10 a 15 m entre si (VALCARCEL, 1985; LLORENS; DOMINGO, 2007).

O transecto SA encontra-se em uma área composta por floresta secundária avançada com cerca de 60 anos, com uso pretérito de extração de madeira e fabricação de carvão vegetal (SOLÓRZANO et al., 2005). O transecto SI ocupa um trecho de mata secundária inicial com 8 anos de idade, em processo de regeneração a partir de um pasto abandonado (SOLÓRZANO et al., 2005, ABREU, 2006). O transecto BD ocupa uma área de transição entre a mata secundária inicial e a floresta secundária avançada. Descrições fitossociológicas mais detalhadas encontram-se em Solórzano et al. (2005), Abreu (2006) e Dias (2008).

A precipitação em aberto foi medida no centro da clareira onde se encontra o transecto SI, área livre de cobertura vegetal. No dia 12 de março de 2010, instalaram-se mais três pluviômetros-controle. Utilizou-se como apoio os dados da estação Rio Centro (22 $00^{\circ}$ $52^{\prime \prime}$ sul, $43^{\circ} 31^{\prime} 08^{\prime \prime}$ oeste, ao nível do mar), situada a $1,8 \mathrm{~km}$ da área amostral. Os dados são registrados com intervalos de $15 \mathrm{~min}$ e foram obtidos através do site da GEORIO $^{5}$.

Os pluviômetros foram confeccionados a partir de tubos de PVC de 100 mm de diâmetro, área de coleta de 79,53 $\mathrm{cm}^{2}$ e peças cortadas de $300 \mathrm{~mm}$ de comprimento. Cada uma dessas peças recebeu uma base "cap", permitindo o armazenamento de água incidente. Essas bases conectam os tubos por encaixe. As fendas entre os encaixes foram seladas com silicone. Esmerilharam-se

\footnotetext{
${ }^{5}$ Fundação Instituto de Geotécnica do Município do Rio de Janeiro. Disponível em: <www2.rio.rj.gov.br/georio/site/alerta/ download.htm>
}

Revista Árvore, Viçosa-MG, v.36, n.5, p.907-917, 2012

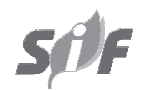


as bordas de cima, tornando-as cortantes para evitar o respingo de superfícies ligeiramente mais amplas. Em cada um dos pluviômetros, foi inserido um funil com malha 1,0 $\mathrm{mm}$ na parte mais estreita para filtrar qualquer material grosseiro. Uma bola de pingue-pongue foi colocada no funil, para amenizar as perdas por evaporação, funcionando como uma "tampa" para a água acumulada no coletor. Os pluviômetros foram fixados em estacas, $80 \mathrm{~cm}$ acima do solo, para evitar contaminação por salpico (SATO, 2008).

As coletas de precipitação e fluxo de atravessamento foram conduzidas após cada evento. Considerou-se como evento dias consecutivos de chuva até um dia inteiro sem chuvas.

Foram desconsiderados os valores de fluxo de tronco. Na literatura de florestas tropicais é recorrente a observação de valores muito baixos e pouco representativos, correspondendo, em média, a apenas $1 \%$ da precipitação acima das $\operatorname{copas}^{6}$ (VALENTE et al., 1997; ARCOVA et al., 2003; COELHO NETTO, 2005; MOURA et al., 2009).

\section{RESULTADOS}

Os resultados observados no Caçambe de precipitação em aberto $(\mathrm{P})$ e dos fluxos de atravessamento (At), segundo a tipologia vegetal, estão na Tabela $2^{3}$. Os valores de precipitação $(\mathrm{P})$ mostraram-se bem superiores à média da zona Oeste do Rio de Janeiro, entre $1.000 \mathrm{e} 1.200 \mathrm{~mm}$ anuais (DERECZYNSKI et al., 2009; TOGASHI, 2009), e também à precipitação total registrada na estação pluviométrica do Rio Centro para o período amostral de $1.931 \mathrm{~mm}$. Resultado esse esperado pela contribuição da altitude (OLIVEIRA; HACK, 2004; DERECZYNSKI et al., 2009), ainda que não se conheça com exatidão a magnitude dessa influência.

A Tabela 2 indica também o aumento da interceptação (I) para folhagens mais densas. O atravessamento (At) geral foi maior na mata secundária inicial (SI) do que na floresta secundária avançada (SA). Resultado amplamente encontrado na literatura em diversos tipos de cobertura (DUNNE; LEOPOLD, 1978; TOBÓNMARIN et al., 2000; COELHO NETTO, 2005; SATO, 2008). Os resultados percentuais são compatíveis com os estudos anteriores realizados na mesma área (CINTRA, 2004; SILVAet al., 2006; NOGUEIRA, 2008), que variaram em interceptação de $13,3 \%$ a $29,7 \%$, assim como os outros estudos em Floresta Atlântica (Tabela 1), que registraram mais frequentemente valores de interceptação entre $10 \%$ e $20 \%$.

\section{DISCUSSÃO}

A chuva acumulada entre cada uma das 27 coletas foi por quatro vezes superior a $200 \mathrm{~mm}$ (Figura 1). Valores entre 50 e $150 \mathrm{~mm}$ foram encontrados em 12 coletas. As outras 11 coletas acumularam menos de $50 \mathrm{~mm}$. As grandes diferenças de amplitude aconteceram no verão e no outono, tendo ocorrido inclusive eventos

Tabela 2 - Valores totais, em mm, de precipitação em aberto (P) e fluxo de atravessamento (At) nas tipologias vegetais secundária inicial (SI), borda (BD) e secundária avançada (SA). Valores, em porcentagem, da média de P e At nas coletas.

Table 2 - Total mm of gross rainfall $(P)$ and throughfall (At) in early secondary sucession (SI), edge (BD) and late secondary sucession (SA). P and At average percentage.

\begin{tabular}{lccccc}
\hline $\mathrm{n}=27$ & Total & Verão $2009 / 2010$ & Outono 2010 & Inverno 2010 & Primavera 2009+2010* \\
\hline P $(\mathrm{mm})$ & 2357,07 & 877,77 & 637,64 & 310,89 & 530,77 \\
At SI $(\mathrm{mm})$ & 2058,21 & 760,34 & 504,03 & 311,97 & 481,87 \\
At BD $(\mathrm{mm})$ & 1930,47 & 699,31 & 557,81 & 289,22 & 384,14 \\
At AS $(\mathrm{mm})$ & 1771,70 & 649,97 & 490,54 & 223,50 & 407,69 \\
At SI $(\%)$ & $0,94 \pm 0,14$ & $0,89 \pm 0,08$ & $0,86 \pm 0,12$ & $1,07 \pm 0,18$ & $0,93 \pm 0,07$ \\
At BD $(\%)$ & $0,89 \pm 0,13$ & $0,91 \pm 0,18$ & $0,91 \pm 0,07$ & $0,93 \pm 0,06$ & $0,82 \pm 0,15$ \\
At AS $(\%)$ & $0,75 \pm 0,07$ & $0,75 \pm 0,05$ & $0,76 \pm 0,07$ & $0,73 \pm 0,10$ & $0,79 \pm 0,06$ \\
\hline
\end{tabular}

${ }^{6}$ A exceção seriam as palmeiras, que pela geometria convergente de suas folhas e galhos podem representar valores em torno de $5 \%$ da chuva acima das copas. 


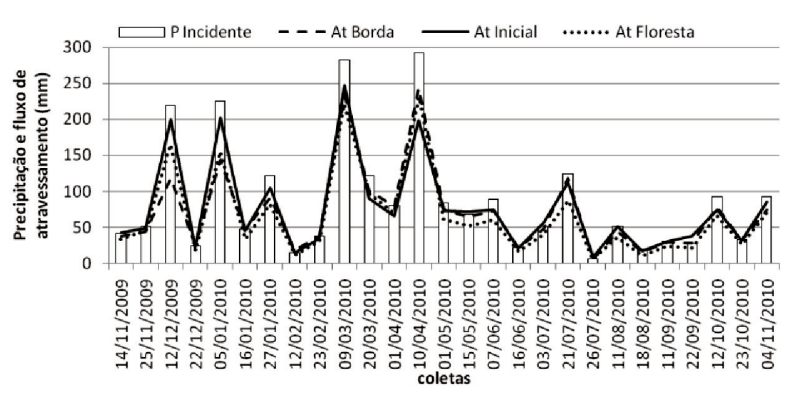

Figura 1 - Precipitação incidente $(\mathrm{P})$ e fluxos de atravessamento (At) médios, segundo tipologias vegetacionais no Caçambe (para cada coleta: $\mathrm{n}$ Borda $=6, \mathrm{n} \mathrm{SI}=$ 6 e n SA = 12)

Figure 1 - Gross rainfall $(P)$ and average throughfall (At) by successional phases in Caçambe. (for each sampling: $n$ edge $=6, n S I=6, n S A=12$ ).

de grande intensidade raros nesta última estação, antecedentes às coletas de 09/03/2010 e 10/04/2010. Baseado na análise de uma série de precipitação entre 1997 e 2008, Togashi (2009) levantou a hipótese de uma tendência crescente da intensidade e volume de chuvas, nos outonos e na primaveras na última década, em particular a partir de 2004. O final da primavera de 2009 e, em especial, o outono de 2010, com o maior evento do período amostral, confirmam essas tendências, que, apesar de contar com grandes chances de se prolongarem, podem se transformar à medida que o comportamento da precipitação é altamente dependente da dinâmica das massas de ar e de outras variáveis, como a temperatura, ventos e umidade.

O fluxo de atravessamento aumentou com o incremento da quantidade de chuva, conforme mostrado na Figura 1. O fluxo de atravessamento na mata secundária inicial (SI), na borda (BD) e na floresta secundária avançada (SA) apresentou estreita relação R $^{2}$ (Figura 2) com a precipitação em aberto. Um indicativo de alta correlação nos dois regimes, ou seja, o fluxo de atravessamento aumenta de acordo com a elevação da altura pluviométrica e diminui à medida que a chuva diminui. Essa alta correlação entre precipitação e fluxo de atravessamento também foi apontada por Oliveira Júnior e Dias (2005) e Arcova et al. (2003). O coeficiente $\mathrm{R}^{2}$ também mostrou correlação entre a precipitação e os fluxos de atravessamento nas diferentes tipologias, se consideradas as estações do ano em separado. O valor de $\mathrm{R}^{2}$, apesar de não se enquadrar no nível de confiança de $95 \%$, ficou muito perto com $94 \%$, um reflexo da irregularidade tipologia Borda na função de interceptação vegetal em relação às outras tipologias.

Segundo a Tabela 2, a interceptação percentual de SA foi sempre superior às demais tipologias, assim como a interceptação absoluta (mm). A Borda e SI tiveram comportamento inconstante. Espera-se que folhagens mais densas interceptem mais, mas na Borda isso não ocorreu percentualmente no verão e no outono. Os fluxos de atravessamento percentual por tipologia vegetal e data da coleta encontram-se detalhados na Figura 3. De forma geral, a interceptação percentual em SI e na Borda aumentou com o incremento da altura pluviométrica por evento, no entanto não alcançando os níveis de SA, com exceção da Borda nos eventos de grande magnitude.

Em SI, praticamente não há dossel para a interceptação de chuva ${ }^{7}$. Em volumes de chuva inferiores a $75 \mathrm{~mm}$ por coleta, verificou-se, por algumas vezes, fluxo de atravessamento superior a $100 \%$. Atribui-se isso a duas possibilidades não diferenciadas neste trabalho: 1) Convergência de gotejamento pela vegetação densa arbustiva, inclusive com armazenamento de água por galhos e folhas entrelaçadas; e 2) A precipitação é altamente heterogênea, considerando-se o número de coletores. Os resultados superiores a $100 \%$ podem ser simplesmente maiores incidências de precipitação em determinados pontos, mesmo porque a turbulência das correntes de ar contribui com a heterogeneidade. Essa heterogeneidade da precipitação contribui com a heterogeneidade no fluxo de atravessamento em Floresta Atlântica. Esses valores reiteram os registros similares em florestas tropicais (LLOYD; MARQUES FILHO, 1988; SCHELLEKENS et al., 1999; TOBÓNMARIN et al., 2000). Além disso, atribuem-se também à heterogeneidade do dossel florestal os altos desviospadrão sobre os fluxos de atravessamento percentuais registrados na Tabela 2 .

A Borda teve baixa interceptação percentual em volumes de chuva inferiores a $90 \mathrm{~mm}$ por coleta (figura 3 ). A tendência de seu comportamento foi similar à de SI, mas com certo aumento da interceptação, visto

\footnotetext{
${ }^{7}$ A baixa interceptação, no entanto, não significa que a precipitação atinge diretamente o solo. Neste trabalho, não foi feito o monitoramento da interceptação pelo extrato herbáceo (gramíneas) nem do piso florestal da mata secundária inicial.
} 


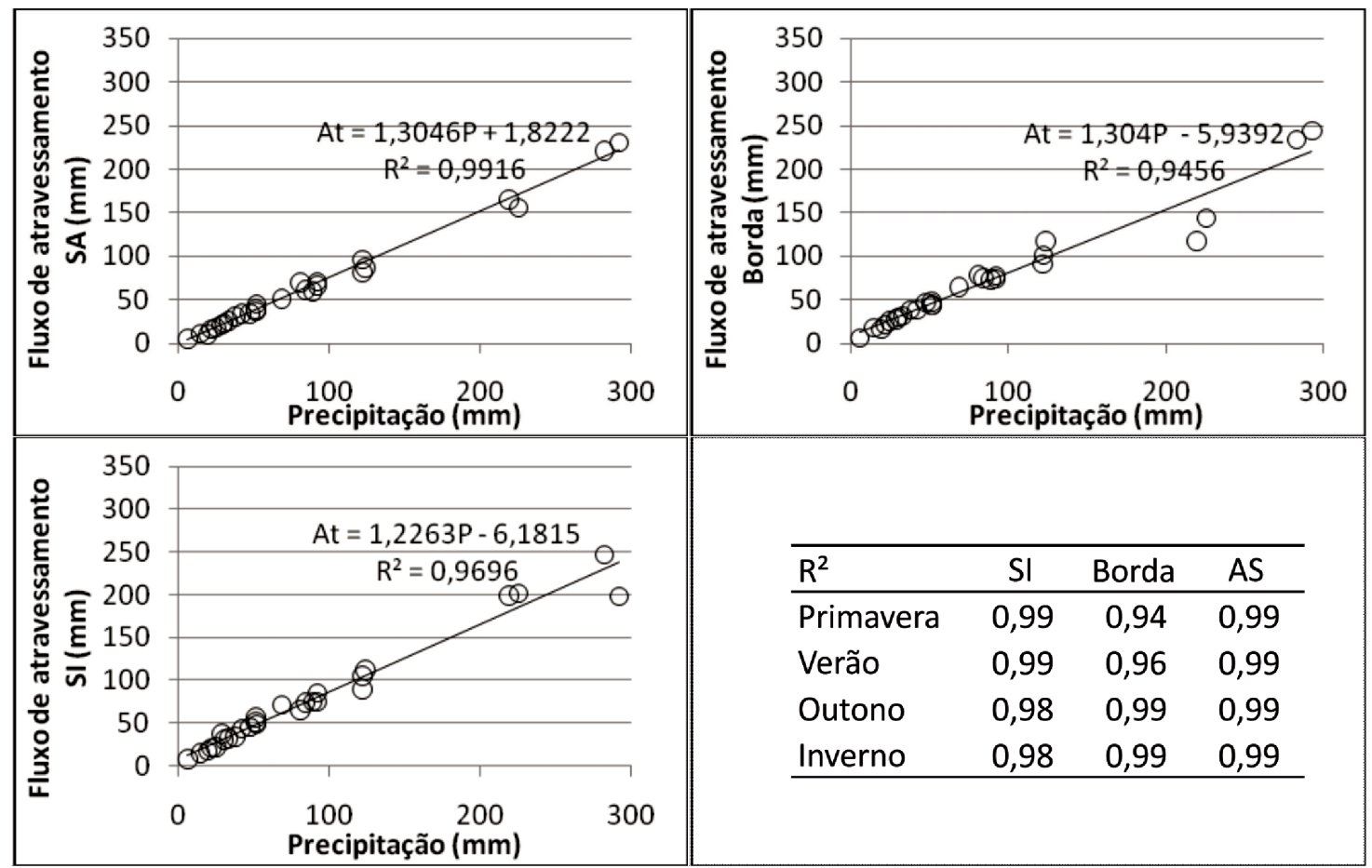

Figura 2 - Correlação no Caçambe entre precipitação (P) e fluxos de atravessamento nas tipologias secundária inicial (SI), borda e secundária avançada (SA).

Figure 2 - Gross rainfall $(P)$ and throughfall $(A t)$ correlation at Caçambe in early secondary sucession (SI), edge and late secondary sucession (SA).

que seu fluxo de atravessamento é geralmente inferior ao de SI. Entretanto, a tipologia SI com 8 anos de idade não apresentou essa funcionalidade. A utilização anterior como pasto provavelmente está relacionada ao retardamento da reestruturação da cobertura vegetal e, consequentemente, da recuperação de níveis mais elevados de interceptação. $O$ atraso no desenvolvimento sucessional em áreas de pasto abandonado ou severamente degradadas é frequentemente relatado na literatura, como em Guariguata e Ostertag (2001).

Já em SA a interceptação percentual foi constante, apenas com ligeiro aumento, mantendo-se como a cobertura vegetal com maior interceptação de variadas magnitudes de chuva.

A floresta na sub-bacia do rio Caçambe constitui um mosaico sucessional determinante na relação hidrológica da encosta local com a baixada de Jacarepaguá, planície adjacente. Uma floresta mais preservada na sub-bacia do rio Caçambe não evitaria os alagamentos em áreas da planície adjacente, como o Rio Centro e seu entorno, mas ajudaria a mitigar o problema. A expansão urbana sobre o remanescente florestal no maciço da Pedra Branca favorece o aumento de perturbações, fazendo prevalecer tipologias vegetacionais como bordas e estágios secundários iniciais. A grande diferença de valores na interceptação vegetal da precipitação por diferentes estágios de sucessão demonstra a importância da conservação florestal.

\section{CONCLUSÃO}

Em geral, o fluxo de atravessamento no Caçambe apresentou padrão de acordo com o descrito pela literatura. Ocorreu aumento da interceptação nas folhagens mais densas. De forma geral, o fluxo de atravessamento foi decrescente ao seguir o gradiente mata secundária inicial, borda e floresta secundária avançada. O fluxo de atravessamento também aumentou 


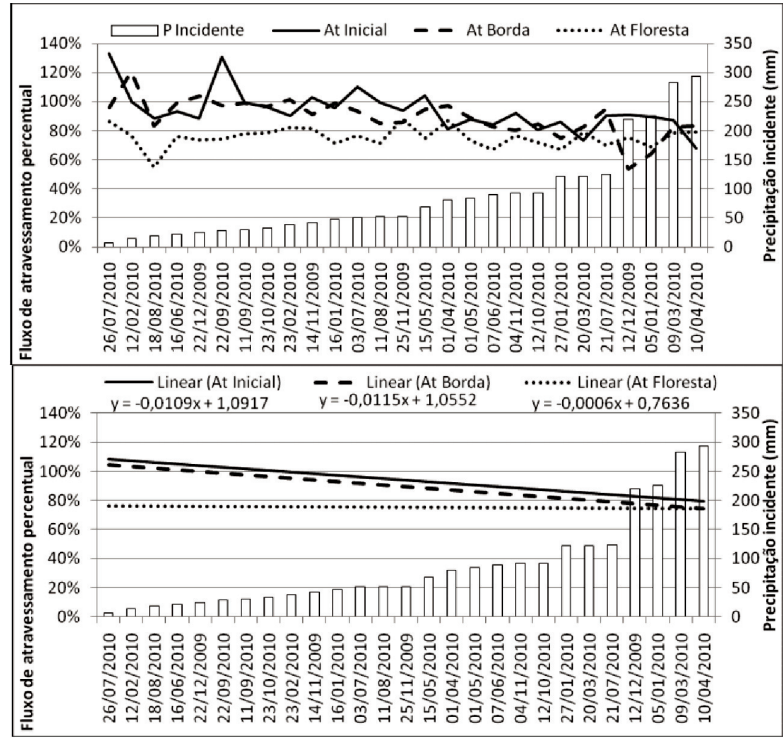

Figura 3 -A) Fluxo de atravessamento (At), percentual nas tipologias secundária avançada (SA), borda e secundária inicial (SI) em ordem crescente de precipitação incidente (P). B) Linhas de tendência respectivas dos fluxos de atravessamento das tipologias vegetais.

Figure $3-A$ ) Throughfall (At) percentage in late secondary sucession (SA), edge and early secondary sucession $(S I)$ ordered by increasing gross rainfall $(P) . B$ ) Throughfall tendency lines by successional phases.

com o incremento da quantidade de chuva, sendo ambos altamente correlacionados $\left(\mathrm{R}^{2}\right)$. Altos desvios-padrão encontrados são atribuídos à heterogeneidade do dossel florestal.

A precipitação incidente na sub-bacia do rio Caçambe apresentou-se bem superior à média histórica da zona Oeste do Rio de Janeiro e aos registros da estação pluviométrica do Rio Centro no período amostral. A altitude pode ter exercido considerável influência no volume de chuvas do Caçambe.

Os resultados percentuais do fluxo de atravessamento no Caçambe, $94 \%$ em SI, $89 \%$ na borda e $72 \%$ em as, são compatíveis com valores encontrados em estudos anteriores na área amostral e na Floresta Atlântica de forma geral. A cobertura vegetal de SA praticamente não interceptou a chuva. A afirmação não se estende ao piso florestal, que não foi monitorado. A cobertura vegetal da borda mostrou baixa interceptação em eventos de pequena intensidade, mas, em relação aos eventos mais intensos, seu atravessamento foi proporcionalmente decrescente, sugerindo, nesse estágio sucessional, um processo de desenvolvimento das funções de interceptação do dossel para eventos maiores. A cobertura vegetal de SA foi a que apresentou a maior interceptação sob diferentes intensidades de chuva.

\section{AGRADECIMENTOS}

À Coordenação de Aperfeiçoamento de Pessoal de Nível Superior/Programa de Suporte à Pós-Graduação de Instituições de Ensino Superior (CAPES/PROSUP) e à Coordenação de Aperfeiçoamento de Pessoal de Nível Superior/ projeto Instituto Nacional de Ciência e Tecnologia Instituto Geotécnico de Reabilitação do Sistema Encosta-Planície (CAPES/projeto INCT-REAGEO), pelo apoio financeiro. Ao Programa de Pós-graduação em Geografia da Pontifícia Universidade Católica (PPGE/PUC-RJ) e aos grupos de pesquisa "Núcleo Interdisciplinar de Pesquisa de Paisagens" (NIPP) e "História Ambiental e Funcionalidade Ecológica da Mata Atlântica no Maciço da Pedra Branca, RJ", onde este trabalho esteve integrado, pelo apoio.

\section{REFERÊNCIAS}

ABREU, J. R. S. P.; OLIVEIRA, R. R.; MONTEZUMA, R. C. M. Dinâmica da serrapilheira em um trecho de floresta atlântica em área urbana do Rio de Janeiro. . Pesquisas Botânicas, n.61, . p.279-291, 2010.

ALMEIDA, A. C.; SOARES, J. V. Comparação entre uso de água em plantações de Eucalyptus grandis e floresta ombrófila densa (mata atlântica) na costa leste do Brasil. Revista Árvore, v.27, n.2, p.159-170, 2003.

ALVES, R. F. et al. Avaliação da precipitação efetiva de um fragmento de Mata Atlântica em diferentes estágios de regeneração no município de Viçosa, MG. Ambiente \& Água, v. 2, n. 1, p.83-93, 2007.

ARCOVA, F. C. S.; CICCO, V.; ROCHA, P. A. B. Precipitação efetiva e interceptação das chuvas por floresta de Mata Atlântica em uma microbacia experimental em Cunha - São Paulo. Revista Árvore, v.27, n.2, p. 257-262, 2003. 
BARBOZA, R. S. et al. Interceptação em Floresta de altitude na serra do Mar, Rio de Janeiro. In: JORNADA DE INICIAÇÃO CIENTÍFICA DA UNIVERSIDADE FEDERAL RURAL RIO DE JANEIRO, 14., 2004, Seropédica. Anais... Seropédica: UFRRJ, 2004. p.317-322.

BERTÉ, L. et al. Contribuição de Floresta Atlântica em regeneração para a deposição de nitrogênio e potássio através da água da chuva. In: SEMINÁRIO NACIONAL DEGRADAÇÃOE RECUPERAÇÃO AMBIENTAL. SOBRADE, Foz do Iguaçu, 2003. Seminario Nacional Degradac'ao e Recuperac'ao Ambiental - Perspectiva Social. Curitiba: FUPEF,p.1-7, 2003.

CICCO, V. et al. Recursos hídricos na Mata Atlântica: estudo de caso do Laboratório de Hidrologia Florestal Walter Emmerich, CunhaSP. In: SEMINÁRIO DE RECURSOS HÍDRICOS DA BACIA HIDROGRÁFICA DO PARAÍBA DO SUL: o Eucalipto e o Ciclo Hidrológico, 1., Taubaté, 2007. Anais... Taubaté: IPABHi, 2007. p.25-33.

CINTRA, T. F. C. Entradas atmosféricas de nutrientes e poluentes em um ecossistema florestal urbano, Maciço da Pedra Branca - RJ. Dissertação (Mestrado em Química) : PUC-RJ, Rio de Janeiro, 133p, 2004.

COELHO NETTO, A. L. Ecossistemas de encostas. Domínio do ecossistema da floresta atlântica de encostas. In: SEMINÁRIO RIO PRÓXIMOS 100 ANOS. Rio de Janeiro: 2007. Disponível em: $<$ http://www.rio.rj.gov.br/ipp/download/ encostas_analuiza_1.pdf $>$. Último acesso em 28 de set. de 2009.

COELHO NETTO, A. L. Hidrologia de encosta na interface com a geomorfologia. In: GUERRA, A. J. T.; CUNHA, S. B. (Orgs.). Geomorfologia : uma atualização de bases e conceitos. 2.ed. Rio de Janeiro: Bertrand Brasil, 2005. p.93-148.

DERECZYNSKI, C. P.; OLIVEIRA, J. S.; MACHADO, C. O. Climatologia da precipitação no município do Rio de Janeiro. Revista Brasileira de Meteorologia, v.24, n.1., 2009. p.24-38.
DIAS, F. C. Efeito de borda em um (contexto de florestas urbanas: (resultantes estruturais de usos pretéritos do solo. 2008. 54p. Dissertação (Mestrado em Ciências Ambientais) Universidade Federal Rural do Rio de Janeiro, Seropédica, 2008.

DUNNE, T.; LEOPOLD, L. B. Water in environmental planning. New York: W. H. Freeman \& Company, 1978.

GUARIGUATA, M. R.; OSTERTAG, R. Neotropical secondary forest succession: changes in structural and functional characteristics. Forest Ecology and Management, v.148, p.185-206, 2001.

IBGE - Instituto Brasileiro de Geografia e Estatística. Manual Técnico da Vegetação Brasileira. Rio de Janeiro - RJ, 1992. 92p.

LLORENS, P.; DOMINGO, F. Rainfall partitioning by vegetation under Mediterranean conditions. A review of studies in Europe. Journal of Hydrology, v.335, n.1/2, p.37-54, 2007.

LLOYD, C. R.; MARQUES-FILHO, A. Spatial variability of throughfall and stemflow measurements in Amazonian rain forest. Agricultural and ForestMeteorology, v.42, p.63-73, 1988.

MENDONÇA, F.; DANNI-OLIVEIRA, I. M. Climatologia: noções básicas e climas do Brasil. São Paulo: Oficina de textos, 2007.

MIRANDA, J. C. Interceptação das chuvas pela vegetação florestal e serrapilheira nas encostas do Maçico da Tijuca: Parque Nacional da Tijuca, RJ. 1992. 100p. Dissertação (Mestrado em Geografia) - PPGG/IGEO/UFRJ, Rio de Janeiro, 1992.

MONTEZUMA, R. C. M.; OLIVEIRA, R. R. Os ecossistemas da Baixada de Jacarepaguá. In: Estudos preliminares do PEU da Vargem. NIMA, 2010. Disponível em $<$ http:// www.nima.puc-rio.br/index.php/grupos-depesquisa/nima-jur/arquivos/1032>. Último acesso em 24 de dez, de 2010.

Revista Árvore, Viçosa-MG, v.36, n.5, p.907-917, 2012 
MOURA, A. E. S. S. et al. Interceptação das chuvas em um fragmento de floresta da Mata Atlântica na Bacia do Prata, Recife, PE. Revista Árvore, v.33, n.3, p.461-469, 2009.

SARAIVA-NETO, P. et al. Avaliação do escoamento superficial de água de chuva em um fragmento de Mata Atlântica no município de Viçosa, MG. In: SEMINÁRIO DE RECURSOS HÍDRICOS DA BACIA HIDROGRÁFICA DO PARAÍBA DO

SUL: Recuperação de Áreas Degradadas, Serviços Ambientais e Sustentabilidade, 2., 2009, Taubaté. Anais...Taubaté: IPABHi, 2009. p.133-140.

NOGUEIRA, E. S. Propriedades físicoquímicas da chuva em um fragmento de floresta urbana no maciço da Pedra Branca - RJ. 2008. 38p.(Monografia) Departamento de Geografia e Meio Ambiente Pontifícia Universidade Católica, Rio de Janeiro, 2008.

OLIVEIRA JÚNIOR, J. C.; DIAS, H. C. T. Precipitação efetiva em fragmento secundário da mata atlântica. Revista Árvore, v.29, n.1, p.9-15, 2005.

OLIVEIRA, R. R. Os cenários da paisagem. In: OLIVEIRA, R. R. (Org.) As marcas do homem na floresta: história ambiental de um trecho de mata atlântica. Rio de Janeiro: PUC, 2005. p.23-34.

OLIVEIRA, R. R.; HACK, L. P. Influência do relevo na distribuição da pluviosidade na Ilha Grande, RJ. Rio de Janeiro:

Eugeniana, 2004. v.28. p.27-37.

OLIVEIRA, R. R.; PENNA-FIRME, R. Resultantes ecológicas de um incêndio florestal na produção de serapilheira de uma mata atlântica de encosta. In: OLIVEIRA, R. R. (Org.) As marcas do homem na floresta: história ambiental de um trecho de mata atlântica. Rio de Janeiro: PUC, 2005. p.152-167.

OLIVEIRA, R. R.; COELHO NETTO, A. L. Captura de nutrientes atmosféricos pela vegetação na Ilha Grande, RJ. Rio de Janeiro: PUC, 2001. p.31-49. (Pesquisa Botânica, 51)

PENHA, H. M. Geologia do Maciço da Pedra Branca. Anais da Academia Brasileira de Ciências, v.53, n.3, p.355-356, 1984.
PROTIL, C. Z. Contribuição de quatro espécies arbóreas ao ciclo biogeoquímico em Floresta Atlântica na Planície Litorânea do Paraná. 2006. 150p. Tese (Doutorado em Engenharia Florestal) Setor de Ciências Agrárias, Universidade Federal do Paraná. Curitiba, 2006.

SATO, A. M. Respostas geohidroecológicas à substituição de pastagens por plantações de eucalipto no médio vale do rio Paraíba do Sul: a interface biota-solo-água. 2008. 160p. Dissertação (Mestrado em Geografia). Rio de Janeiro: PPGG/IGEO/UFRJ, 2008.

SCHEER, M. B. Fluxo de nutrientes pela precipitação pluviométrica em dois trechos de floresta ombrófila densa em Guaraqueçaba, Paraná. Revista Floresta, v.39, n.1, p.117-130, 2009.

SCHELLEKENS, J. et al. Modelling rainfall interception by a lowland tropical rain forest in northeastern Puerto Rico. Journal of Hydrology, v.225, n.3/4, p.168-184, 1999.

SILVA, E. et al. Interceptação e propriedades físico-químicas da precipitação na mata atlântica do Maciço da Pedra Branca, RJ. In: SIMPÓSIO BRASILEIRO DE GEOGRAFIA FÍSICA

APLICADA, 10., 2006. Anais... Disponível em: <http://geografia.igeo.uerj.br/xsbgfa/cdrom/ eixo3/3.4/031/031.htm>. Último acesso em 01 de dez. de 2009.

SOLÓRZANO, A.; OLIVEIRA. R. R.; GUEDESBRUNI, R. História ambiental e estrutura de uma floresta urbana. In: OLIVEIRA, R. R. (Org.) As marcas do homem na floresta: história ambiental de um trecho de mata atlântica. Rio de Janeiro: PUC, 2005. p.81-106.

SOUZA, L. C. Dinâmica de nutrientes na precipitação, em solução de solo e lençol freático em três tipologias florestais sobre espodossolo, no litoral do Paraná. 2006. 131p. Tese (Doutorado em Engenharia Florestal) - Setor de Ciências Agrárias, Universidade Federal do Paraná, Curitiba, 2006. 
SOUZA, V. V. et al. Análise da qualidade das águas das precipitações em aberto e efetiva em um fragmento secundário da Mata Atlântica, no município de Viçosa, MG. Revista Árvore, v.31, n.4, p.737-743, 2007.

THOMAZ, E. L. Avaliação de interceptação e precipitação interna em capoeira e floresta secundária em Guarapuava-PR. Geografia

Revista do Departamento de Geociências, v.14, n.1, p.47-60, 2005.

TOBON-MARIN, C.; BOUTEN, I. W.; DEKKER, S. Forest floorwater dynamics and root wateruptake in four forestecosystems in northwestAmazonia. Journal of Hydrology, n.237, v.3/4, p.169-183, 2000.

TOGASHI, H. F. Comportamento pluviométrico das vertentes sul e leste do maciço da Pedra Branca, zona oeste do município do Rio de Janeiro, RJ: 19972008. Monografia (Especialização) - Departamento de Geografia e Meio Ambiente - Pontifícia Universidade Católica, Rio de Janeiro, 2009.
VALCARCEL, R. Balanço hídrico no ecossistema florestal e sua importância conservacionista na região ocidental dos Andes Venezuelanos. In: SEMINÁRIO SOBRE ATUALIDADES E PERSPECTIVAS FLORESTAIS, 1985, Curitiba. Anais... Curitiba: 1985. p.32-35.

VALENTE, F; DAVID J. S.; GASH, J. H. C. Modelling interception loss for two sparse eucalypt and pine forests in central Portugal using reformulated Rutter and Gash analytical models. Journal of Hydrology, v.190, n.1/2, p.141-162, 1997.

WALLACE, J.; McJANNET, D. Modelling interception in coastal and montane rainforests in northern Queensland, Australia. Journal of Hydrology, v.348, n.3/4, p.480-495, 2008.

ZAÚ, A. S.; COELHO NETTO, A. L.; OLIVEIRA, R. R. Cobertura florestal: degradação, resultantes ecológicas e efeitos de borda no Parque Nacional da Tijuca, Rio de Janeiro/RJ. In: ENCONTRO IALE-BR, 1., 2005. Rio de Janeiro/ Vale do Paraíba do Sul/São Paulo, 2005. 
